Cuadernos de Historia Contemporánea

ISSN: 0214-400X

http://dx.doi.org/10.5209/CHCO.56281

\title{
Historia oral de la guerra civil y el franquismo en Andalucía ${ }^{1}$
}

\section{Sofía Rodríguez López ${ }^{2}$}

La historia oral está relacionada desde sus orígenes con la historia escrita "desde abajo", y en este caso el término abajo cobra dos sentidos: la historia escrita al sur de la Península Ibérica, en Andalucía, y la historia dedicada a las gentes del sur, doquiera que el sur se encuentre... Ese sur pobre, rural y deprimido, que suele caracterizar a las naciones del Mediterráneo, frente a la próspera Europa del norte; o el cono sur latinoamericano, frente a los omnipotentes Estados Unidos y los países de la Commonwealth. Es una historia vinculada a la vida cotidiana y las mentalidades de la gente corriente, a ese concepto de "pueblo" de la historia social como gente sin medios, sin apenas formación ni esperanzas de futuro. En la historiografía andaluza, aborda dos coyunturas extraordinarias que marcan inevitablemente la sociedad actual: la traumática guerra civil y la, para muchos no menos traumática, dictadura franquista ${ }^{3}$.

\section{Historia del presente vs. memoria histórica}

Aunque a menudo se vincule a la recuperación de la memoria histórica, la investigación sobre "el tiempo presente", el de las generaciones vivas, no debe confundirse con lo que la "memoria histórica" tiene en nuestro país de movimiento social. Como investigadores podemos hacer historia crítica y fundamentada en fuentes de todo tipo: escritas, visuales, orales y secundarias o bibliográficas. Como ciudadanas y ciudadanos, a menudo participamos en las acciones promovidas por los familiares de las víctimas, pero no todo lo que publicamos es memoria histórica, como tampoco levantar un monumento, exhumar una fosa o escribir en la prensa sobre los represaliados del franquismo es historia.

Son dos ámbitos que, resultando complementarios, debemos distanciar y distinguir. Nuestra obligación es interpretar las fuentes para extraer unas conclusiones y un relato contrastable, a través del ejercicio metodológico. Cuando a los historiadores nos piden colaboración en un proyecto de memoria histórica, en cambio, nuestra labor como documentalistas está al servicio de un encargo definido, cuyo propósito

1 Una primera versión del texto fue leída como discurso de ingreso en la Academia Andaluza de la Historia (11 de junio de 2016). Grupo PAI-HUM 331 de la Universidad de Málaga "Investigaciones Históricas Andaluzas".

2 Universidad Carlos III de Madrid (España)

Email: sofrodri@hum.uc3m.es

3 Cruz, Rafael: En el nombre del pueblo. República, rebelión y guerra en la España de 1936, Madrid, Siglo XXI, 2006. 
no es el encaje intelectual en un debate académico, sino una demanda de justicia y reparación, de verdad. Josefina Cuesta incidió ya en ello hace veinte años, hablando de la interacción entre la calle y el enfoque científico de la memoria. Un camino roturado en 1925 por Maurice Halbwacks, con su epistemología sobre la "sociología de la memoria", y ensanchado por Pierre Nora, entre 1984-1992, hacia la reinterpretación de la historia nacional a través de los "lugares de memoria". En el estado de la cuestión elaborado para Ayer, Cuesta comenzaba con una cita de Dupront de 1960: «la memoria colectiva es la materia misma de la historia», y recorría las posibilidades de la "historia de la memoria" introducida en España por su grupo de trabajo en la Universidad de Salamanca (1993), recomendando la importante obra de Paloma Aguilar sobre la memoria y el olvido de nuestra guerra civil (1995-1996) ${ }^{4}$.

Un lustro más tarde, Julio Aróstegui definió el recién inaugurado siglo XXI como un "tiempo de memoria", en tanto que reivindicación pública, hablándose ya de su propia crisis o los retos de futuro, y poniendo el foco en su dimensión como «formas sociales permanentemente construidas y reestructuradas... y su relación con la percepción y la escritura de la Historia $\rangle^{5}$. De lo que no cabe duda, es que tanto el pionero Halbwachs como sus seguidores en la sociología francesa, desde Joutard hasta Ricoeur, demostraron muy pronto la diversidad, flexibilidad y autocomplacencia de las memorias colectivas, frente a la existencia de una sola historia, cuya función es crítica ${ }^{6}$.

\section{Paradigmas explicativos de las fuentes orales}

El paradigma explicativo de la causalidad social procedente del marxismo sufrió una revisión hace ya décadas, que ha terminado por sustituirlo por otros que tienen que ver con el subjetivismo y la explicación intencional de las acciones humanas, con modelos alternativos al debate entre estructura social versus individuo, o al de materialismo frente a idealismo. Sería, por ejemplo, para M.Á. Cabrera, la historia post-social, afectada por la cultura y un mayor protagonismo de los sujetos históricos ${ }^{7}$.

Cuando parece que ya se ha dicho todo sobre la guerra civil y el franquismo, las fuentes orales brindan a esa historia, a mi juicio, otro caudal de posibilidades. Frente a los revisionismos teóricos y las meras compilaciones de testimonios, el estudio de la oralidad y la memoria en sí mismas sugiere nuevas perspectivas. Nos permiten cuestionar los márgenes de acción individual en los marcos de violencia estructural que parecían determinar las vidas de sus protagonistas hasta anular

4 Cuesta, Josefina: "Memoria e historia. Un estado de la cuestión”, Ayer, 32 (1998), pp. 203-246 y La odisea de la memoria. Historia de la memoria en España. Siglo XX. Madrid, Alianza, 2008; Aguilar, Paloma: La memoria histórica de la guerra civil española (1936-1939): un proceso de aprendizaje político. Madrid, Instituto Juan March, 1995 y Memoria y olvido de la guerra civil. Madrid, Alianza, 1996.

5 Aróstegui, Julio: "Retos de la memoria y trabajos de la historia", Pasado y Memoria, 3, 2004, pp. 5-58 y Aróstegui, Julio y Godicheau, François: Guerra Civil. Mito y memoria. Madrid, Marcial Pons, 2006.

6 Allier, Eugenia: "Los Lieux de Mémoire: una propuesta historiográfica para el análisis de la memoria", Historia y Grafia, 31, 2008, pp. 165-192.

7 Cabrera, Miguel Ángel: "La crisis de la historia social y el surgimiento de una historia post social", Ayer, 51, 2003, pp. 201-224. Una historia heredera de los marxistas británicos como E.P. Thompson, y cercana a la microhistoria impulsada desde Italia por Carlo Ginzburg, o la historia de la vida cotidiana de la Alltagsgeschichte alemana. 
su voluntad o su poder de resistencia. Las experiencias de guerra y posguerra, narradas por los últimos supervivientes de esa "generación perdida", construyen un corolario sobre las condiciones materiales de existencia, las mentalidades y el imaginario de una época, pero también sus dudas, sus egoísmos, sus contradicciones y capacidad de agencia para oponerse. Denotan actitudes sociales y dibujan identidades de clase, género, vecindad, creencias o ideología política, difíciles de captar por otros medios.

El análisis de las entrevistas demuestra, además, la construcción discursiva del pasado, o la interpretación de nuestras trayectorias biográficas en sintonía con el presente y los cambios experimentados con el tiempo. El uso de la palabra se ha convertido así en válvula de escape para la objetivación de un trauma colectivo, la guerra y la dictadura. Una forma de expresión para la gente corriente y ágrafa, cercana a la mayéutica socrática: ese debate metódico por el cual se ejercitaba el "arte de parir ideas" entre personas que nunca habían reflexionado sobre su pasado como experiencia histórica, y daban forma así a sus pensamientos. Una disertación que surge también de la necesidad de confesarse, en el epílogo de sus vidas (la remembranza), y que convierte a sus interlocutores en albaceas privilegiados de ese legado. El éxito profesional de nuestro trabajo dependerá de que logremos hacer con el testimonio historia, y no una verdad revelada, un ejercicio cómplice o victimista ${ }^{8}$.

El uso de las fuentes orales en la historiografía contemporánea de Andalucía es cada vez más frecuente, aunque no siempre cumpla las exigencias epistemológicas de, por ejemplo, Kate Moore, Alessandro Portelli, Luisa Passerini, Paul Thompson, Ronald Fraser, Daniel Bertaux o Philippe Joutard. En España, han destacado los nombres de María Carmen García-Nieto, Mercedes Vilanova, Cristina Borderías, Miren Llona, Pilar Díaz, Pilar Domínguez o José María Gago (Seminario de Fuentes Orales de la Universidad Complutense), además de las importantes aportaciones desde la sociología de Cristina Santamarina y José Miguel Marinas, entre otros $^{9}$. En ocasiones, un proyecto ambicioso y de larga duración como el de los exiliados de la República en México dio lugar a diversos enfoques y trabajos: des-

8 Este tipo de historia social de la guerra y el franquismo con fuentes orales se ha visibilizado en España a través de distintas publicaciones monográficas o periódicas, entre las que merece destacarse el papel de la revista Historia, Antropología y Fuentes Orales, editada por la Universitat d'Barcelona desde 1989, o las Jornadas "Historia y Fuentes Orales" del Seminario de la UCM, publicadas desde 1993 con la Fundación Cultural Santa Teresa en Ávila, y editadas por Trujillano, Díaz y Sánchez: Memoria y Sociedad en la España Contemporánea (1993); Historia y Memoria del Franquismo. Actas IV Jornadas (1997); Testimonios orales y escritos. España 1936-1996. Actas V Jornadas (1998) o Memoria e identidades. Actas VII Jornadas (2000).

9 Algunas de sus obras de cabecera en castellano: Moore, Kate: "Perversión de la palabra: la función de las transcripciones en la historia oral", Boletín IOHA "Palabras y Silencios", 1/1, 1997; Passerini, Luisa: Storia Orale. Vita quotidiana e cultura materiale delle classi subalterne. Turín, Rosenberg\&Sellier, 1978; Portelli, Alessandro: La historia oral. Buenos Aires, CEAL, 1991; Fraser, Ronald: Recuérdalo tú y recuérdalo a otros. Historia Oral de la Guerra Civil Española. Barcelona, Crítica, 1979; Thompson, Paul: La voz del Pasado. Valencia, Alfons el Magnànim, 1988; Bertaux, Daniel: "Los relatos de vida en el análisis social”; Historia y Fuente Oral, 1, 1989; Joutard, Philippe: Esas voces que nos llegan del pasado. México, Fondo de Cultura Económica, 1986; Vilanova, Mercedes: "Creación y Utilización de la Fuente Oral”, en García-Nieto, Ma Carmen et alii: Historia, Fuente y Archivo Oral. Madrid, MEC, 1990; Borderías, Cristina: "La Historia Oral en España a mediados de los noventa", Historia y Fuente Oral, nº13, 1995, pp. 113-129; Marinas, J y Santamarina, C., La Historia Oral: métodos y experiencias. Madrid, Debates, 1993; Llona, Miren (ed.): Entreverse. Teoría y metodología práctica de las fuentes orales. Bilbao, Universidad del País Vasco, 2012; Folguera, P., Díaz, P., Domínguez, Gago, J.M.: El mundo del trabajo en RENFE: Historia oral de la infraestructura. Madrid, Fundación de los Ferrocarriles Españoles, 2003. 
de los inmigrantes catalanes en el D.F., abordado por Dolors Plá, al de las mujeres de Pilar Domínguez. En otras, especialistas en esta metodología la han volcado en estudios de caso sobre la trayectoria de una ciudad o un barrio, como Palomeras, en Madrid; Schamann en Las Palmas, o el Gran Bilbao ${ }^{10}$.

En contraste con esos focos de mayor densidad investigadora (Barcelona, País Vasco, Madrid), y aunque hayan recurrido frecuentemente a ellas historiadores e historiadoras andaluces, aún no existe en Andalucía una escuela como tal de historiadores orales, de solidez teórica y proyección exterior como aquellos que están asociados a la red IOHA (International Oral History Association).

Con todo, en Memorias de Los Nadie, ${ }^{11}$ yo misma traté de proceder a hacer historia a través de una serie de entrevistas realizadas para un proyecto de memoria histórica, el Mapa de Fosas en Andalucía. Los testimonios pertenecían en su abrumadora mayoría a vencidos de la guerra civil, y en muchos casos a víctimas directas o indirectas de la represión franquista. Dado que el propósito era que las memorias fueran representativas de una mayoría de la población rural y desheredada, incluso apolítica, se hizo necesario intervenir sobre la muestra, haciendo una severa selección de los testimonios recopilados, analizándolos, cruzándolos entre sí y cuestionándolos, a la luz de otras informaciones halladas en los archivos y hemerotecas ${ }^{12}$.

Estas dieron pie para hablar de otros muchos temas, aparte de la militancia y la violencia revolucionaria o sumarísima, y ampliar el arco cronológico desde la Gran Guerra hasta el final de la Autarquía y lo que se conoce como segundo franquismo. Hitos que en Andalucía tuvieron un enorme valor de ruptura, por coincidir con dos oleadas migratorias: la de los indianos trasatlánticos que se fueron a hacer las "Américas", y la de esos miles de emigrantes andaluces, que protagonizaron el éxodo rural hacia los suburbios de las capitales españolas, o llegaban en ferrocarril a Centroeuropa. Lo que diferencia esta investigación de otras muchas llevadas a cabo sobre el periodo es el papel protagonista otorgado precisamente a las fuentes orales, no como mera apoyatura de las tesis sostenidas en el libro, sino como hilo argumental de las mismas. Un tratamiento hermenéutico de las entrevistas como fuentes de la "historia discursiva" y no sólo como "memoria histórica"13.

\section{Guerra y franquismo}

Menos trabajo cuesta advertir la existencia en Andalucía de dos o tres focos de investigación sobre la crisis de los años treinta, el conflicto armado y la dictadura, con o sin fuentes orales. Casi todos trabajan a partir de la historia local, si bien en

10 Pla, Dolors: Els exiliats catalans a Mèxic: un estudi de la immigració republicana. Catarroja, Afers, 2000 y Domínguez, Pilar: Voces del exilio: mujeres españolas en México (1939-1950). Madrid, Dirección General de la Mujer, 1994; García-Nieto, Ma Carmen (ed.): La palabra de las mujeres. Una propuesta didáctica para hacer historia (1931-1990). Madrid, Ed. Popular, 1991; Iglesias, Ma Luisa, Memoria de la ciudad: Schamann 19401970. Historia oral de un barrio. Las Palmas, Idea, 2009; Llona, Miren: Entre señorita y garçonne. Historia oral de las mujeres bilbaínas de clase media (1919-1939). Málaga, Atenea, 2002 o Dios, Eider de, Clase, Género e Identidad a través del Servicio Doméstico en el Gran Bilbao durante el franquismo (Tesis UPV, 2016)

11 Rodríguez López, Sofía: Memorias de Los Nadie. Una historia oral del campo andaluz (1914-1959). Sevilla, CENTRA, 2015, 557 págs.

12 Rodríguez López, Sofía: "Los secretos de la memoria. Guerra Civil, Franquismo y Fuentes Orales en Almería", Pasado y Memoria, 7, 2008, pp. 263-283.

13 Geertz, Clifford: La interpretación de las culturas. México, Gedisa, 1987. 
la Universidad de Granada se han centrado en el denominado "Sureste peninsular", con muestreos de aquella provincia, Almería y Jaén. Miguel Gómez Oliver, Octavio Ruiz-Manjón, Rafael Gil Bracero y Francisco Cobo Romero, aglutinaron en el Campus de La Cartuja a un grupo de jóvenes investigadores dedicados al mundo rural y las relaciones políticas y socioeconómicas del primer y segundo franquismo. Teresa Ortega, Miguel Ángel del Arco o Claudio Hernández, representan hoy referentes en ese ámbito, gracias también a su conexión con el Cañada Blanch Centre de Londres, dirigido por Paul Preston, y al éxito de divulgación de sus trabajos en la editorial granadina Comares, donde hoy publican especialistas de importancia nacional e internacional ${ }^{14}$.

En Granada se doctoraron también dos almerienses representantes de esa generación, Rafael Quirosa y Antonio Cazorla, cuyas tesis versaron precisamente sobre la guerra civil y la implantación del Nuevo Estado en dicha provincia, a nivel fundamentalmente político y económico. Aspectos que más tarde profundizarían Eusebio Rodríguez Padilla, Sofía Rodríguez López y Óscar Rodríguez Barreira, al hablar de la represión militar, la movilización femenina y las prácticas de resistencia. El Grupo de Estudios del Tiempo Presente ha enlazado además estas problemáticas con la política local y los medios de comunicación del tardofranquismo a través de Mónica Fernández o Áurea Vidal, entre otros ${ }^{15}$.

Algo similar sucedió en Málaga a través de los discípulos de Antonio Nadal y sus primeros trabajos sobre la guerra civil, con Encarna Barranquero, Lucía Prieto y Matilde Eiroa, que publicaron sus tesis doctorales en el mismo año (1992), y abordaron con testimonios de primera mano la supervivencia de posguerra en Málaga. Les siguieron otros como Juan Antonio Ramos o Cristian Cerón, que trataron la consolidación y evolución del franquismo hasta 1959, o Carmen Rosa García Ruiz que enlaza esa coyuntura con los movimientos sociales de la Transición a la democracia $^{16}$. Otro tanto sucede con Fernando Arcas, director del Grupo de "Historia, imagen

14 Algunos ejemplos: Gómez, Miguel y Ruiz-Manjón, Octavio (coords.): Los nuevos historiadores ante la Guerra Civil española. Granada, Diputación Provincial, 1990; Gil, Rafael: Revolucionarios sin revolución: marxistas y anarcosindicalistas en guerra, Granada-Baza, 1936-1939. Granada, UGR, 1998; Cobo Francisco y Ortega, Teresa: Franquismo y posguerra en Andalucía Oriental. Granada, UGR, 2005; Arco, Miguel A. del: El primer franquismo en Andalucía oriental (1936-1951): poderes locales, instauración y consolidación del régimen franquista. Granada, UGR, 2005; Hernández, Claudio: Franquismo a ras de suelo. Zonas grises, apoyos sociales y actitudes durante la dictadura (1936-1976). Granada, UGR, 2013.

15 Quirosa, Rafael: Politica y Guerra Civil en Almería. Almería, Ed. Cajal, 1986; Cazorla, Antonio: Desarrollo sin Reformistas. Dictadura y campesinado en el nacimiento de una nueva sociedad en Almería, 1939-1975. Almería, IEA, 1999; Rodríguez, Sofía: La Sección Femenina y la sociedad almeriense durante el franquismo. Almería, UAL, 2005; Rodríguez, Eusebio: La represión franquista en Almería, 1939-1945. Almería, Arráez, 2005; Rodríguez, Óscar: Poder y actitudes sociales durante la postguerra en Almería: (1939-1953). Almería, UAL, 2007 y Rodríguez, Óscar: Miserias del poder. Los poderes locales y el Nuevo Estado franquista, 19361951. Valencia, PUV, 2013; Fernández, Mónica: Los socialistas de Almería durante la Transición: de la clandestinidad al poder. Almería, Arráez, 2006; Ramírez, Antonio: El optimismo de los desesperados. Historia del PCE en Almería (1922-1939). Almería, UAL, 2016.

16 Nadal, Antonio: Guerra Civil en Málaga. Málaga, Arguval, 1984; Barranquero, Encarnación: La implantación del Nuevo Estado en Málaga (1937-1939). Málaga, UMA, 1992; Prieto, Lucía: Conflictividad social, guerra y revolución, estudio de una comunidad andaluza: Marbella (1931-37). UMA, 1992; Eiroa, Matilde: Málaga tras la guerra: el asentamiento del sistema franquista (1939-1942). UMA, 1992 y Viva Franco: hambre, racionamiento, falangismo: Málaga, 1939-1942. Málaga, 1995; Barranquero, Encarnación y Prieto, Lucía: Así sobrevivimos al hambre. Estrategias de supervivencia de las mujeres en posguerra española. Diputación de Málaga, 2003; Ramos, Juan Antonio: Guerra Civil en Málaga, 1936-1937. Revisión histórica. Málaga, Algazara, 2003; Cerón, Cristian: La paz de Franco, la posguerra en Málaga: desde los oscuros años 40 a los grises años 50. UMA, 2007; García, Carmen Rosa: Franquismo y Transición en Málaga, 1962-1979. UMA, 1999. 
y memoria de Andalucía", y cuyo último libro se titula Yo estaba allí. Una historia oral de la Guerra Civil y el Franquismo en la provincia de Málaga (2011), o con Cristóbal García Montoro, coordinador de la obra Voces de la memoria. Retazos de vida en Málaga (2002), y director de la tesis de José Ma Azuaga sobre "La Guerrilla antifranquista de Granada y Málaga (1948-1952)".

El resto de provincias andaluzas, si bien cuentan con obras de referencia para conocer el desarrollo de su historia más reciente, no están comprendidas en una línea o equipo de investigación que represente a la Baja Andalucía, en el periodo que nos ocupa. Citaremos algunos de ellos, como el propio Francisco Cobo, que empezó trabajando sobre el Jaén republicano, al igual que Luis Garrido con las colectivizaciones, y las breves incursiones de Francisco Acosta y David Martínez, desde la historia social y económica del XIX en la del $\mathrm{XX}^{17}$.

En Córdoba, donde sigue vigente la influencia de José Manuel Cuenca Toribio en trabajos sobre la historia de la Iglesia española y de Andalucía desde la guerra civil al 23F, Francisco Moreno Gómez se convirtió muy pronto en un referente para los estudios sobre la represión y la guerrilla. Por su parte, Antonio Barragán Moriana se ha especializado en los últimos años en la persecución económica de los vencidos ${ }^{18}$.

En Huelva el panorama abarca desde las obras de Francisco Espinosa Maestre sobre la "justicia" de Queipo de Llano, hasta la más reciente tesis de Pedro Feria acerca de la represión económica del TRP, y las múltiples contribuciones de Inmaculada Cordero y Encarna Lemus sobre el exilio o la reconstrucción del PCE en la posguerra, las relaciones internacionales del tardofranquismo, y la obra Cárcel de amor, exquisito relato de esta última sobre la correspondencia entre una pareja de presos antifascistas ${ }^{19}$.

En Cádiz, Virtudes Narváez se ocupó del papel de las mujeres en el conflicto y Alicia Domínguez de la represión militar, mientras José Luis Gutiérrez cuenta en su haber diversos trabajos acerca del anarquismo y la memoria histórica. Sin embargo,

17 Cobo, Francisco: La conflictividad campesina en la provincia de Jaén durante el periodo 1931-1939. Granada, UGR, 1991 o La guerra civil y la represión franquista en la provincia de Jaén (1936-1950). Jaén, IEG, 1994; Garrido, Luis: Colectividades agrarias en Andalucía: Jaén (1931-1939). Madrid, Siglo XXI, 1979; Acosta, Francisco: "Democracia y mundo rural en Andalucía 1890-1936: propuestas para la revisión crítica de algunos tópicos historiográficos", Actas del X Congreso de la AHC, 2011 o Martínez, David y Cruz, Salvador: Protesta obrera y sindicalismo en una región "idílica”: historia de Comisiones Obreras en la provincia de Jaén. UJA, 2003.

18 Desde la obra seminal de Francisco Moreno con Tuñón de Lara, La guerra civil en Córdoba (1936-1939). Alpuerto, 1985 o Córdoba en la posguerra: (la represión y la guerrilla, 1939-1950). Córdoba, Francisco Baena, 1987 hasta Trincheras de la República, 1937-1939: desde Córdoba al Bajo Aragón, al destierro y al olvido. Córdoba, El Páramo, 2013; Barragán, Antonio: El "regreso de la memoria": control social y responsabilidades políticas: Córdoba 1936-1945. El Páramo, 2009 o Crisis del franquismo y transición democrática en la provincia de Córdoba. UCO, 2005. De José Manuel Cuenca citaremos sólo: La Andalucía de la transición (1975-1984): politica y cultura. Madrid, Mezquita, 1984; La guerra civil de 1936. Madrid, Espasa Calpe, 1986; Nacionalismo, franquismo y nacionalcatolicismo. Actas, 2008.

19 Espinosa, Francisco: La justicia de Queipo (violencia selectiva y terror fascista en la II División en 1936): Sevilla, Huelva, Cádiz, Córdoba, Málaga y Badajoz. Montilla, 2000; Cordero, Inmaculada et alii: Los transterrados y España. Un exilio sin fin. Huelva, UHU, 1996; Lemus, Encarnación: Cárcel de amor: una historia real en la dictadura franquista. Fundación El Monte, 2005; "El final de los vencidos: el exilio en la memoria de la izquierda andaluza", en Andalucia y la Guerra Civil: estudios y perspectivas. USE, 2006, pp. 145-159; (coord. con Rafael Quirosa) La transición en Andalucía. UHU, 2002; "Andalucía bajo el franquismo", Historia de Andalucía contemporánea. UHU, 1998, pp. 457-495; "Permanencia y reconstrucción del PCE en Andalucía durante la postguerra (1939-1949)", Espacio, Tiempo y Forma, 11, 1998, pp. 483-506 y (con Inmaculada Cordero), "El contramodelo femenino del franquismo: clandestinas andaluzas durante la postguerra", en Exilio femenino. UHU, 1999, pp. 125-144. 
el manual de Sílex sobre Historia de Cádiz (2005), dedica sólo un capítulo al siglo XX, eso sí, con una interesante bibliografía comentada de José Luis Millán. En ella aparecen libros testimoniales como los de Fernando Guilloto sobre la guerra, o el que Manuel Pérez Regordán dedica al maquis gaditano, siendo mucho más prolijas las publicaciones sobre la transición del grupo dirigido por Julio Pérez Serrano ${ }^{20}$.

Finalmente, en Sevilla destacan los estudios de fascismo rural de Alfonso Lazo y José Antonio Parejo, o los de José M ${ }^{\mathrm{a}}$ García Márquez y Aurelio Peral sobre la represión, junto a los llevados a cabo en la Universidad Pablo de Olavide por Juan Ortiz Villalba, autor de la principal monografía de la rebelión militar en Sevilla, y el antropólogo Ángel del Río, que ha abordado con otros impulsores de la memoria histórica como Cecilio Gordillo, el Canal de los Presos del Bajo Guadalquivir y los andaluces de Mauthausen ${ }^{21}$. Dos de las últimas publicaciones al respecto se deben a José Díaz Arriaza con Francisco Moreno: Ni localizados ni olvidados: Las Fosas del Cementerio San Fernando de Sevilla, 1936-1958, y al onubense Espinosa Maestre con Francisco Gavira y Emilio Silva: Marchena 1936, Verano de Terror; Marchena 2016, Primaveras de Memoria, ambas aparecidas en 2016 en Aconcagua Libros.

A todos estos nombres habría que sumar otras individualidades destacadas en el estudio de un aspecto particular de la dictadura, como la violencia simbólica y de género, caso de la filóloga Pura Sánchez y sus Individuas de dudosa moral. Lo mismo ocurre con los antropólogos y pedagogos que indagaron sobre las políticas paternalistas del franquismo en sus doctorados, como Assumpta Sabuco y su delicioso estudio sobre la Isla del Arroz, tan en boga por el éxito de la película La Isla Mínima y las fotografías de Atín Aya; o el de Amalia Morales, sobre el trabajo social de Sección Femenina en Granada. Una línea de trabajo similar a la de Francisco Sánchez Llamas y Heliodoro Pérez, que leyeron en 1998 y 2003 sus tesis sobre las cátedras ambulantes en Málaga y Huelva, respectivamente ${ }^{22}$.

También hay autores que comenzaron haciendo historia local y se han convertido hoy en referentes para los hispanistas en el estudio del franquismo, como Antonio Cazorla Sánchez. O investigadores que han reparado desde fuera en las posibilida-

20 Narváez, Virtudes: La imagen de la mujer en la Guerra Civil: Un estudio a través de la prensa gaditana (1936-1939). Cádiz, Quórum, 2009; Domínguez, Alicia: El verano que trajo un largo invierno: la represión politico-social durante el primer franquismo en Cádiz, 1936-1945. Cádiz, Quórum, 2004; Gutiérrez, José Luis: La Idea revolucionaria. El anarquismo organizado en Andalucía y Cádiz durante los años treinta. Madrid, 1993; Guilloto, Fernando: Cinco años en la historia de Cádiz (1936-1940). 1988; Pérez, Manuel: El maquis en la provincia de Cádiz. 1987; Pérez Serrano, Julio: Cádiz ciudad desnuda: cambio económico y modelo demográfico en la formación de la Andalucía contemporánea. Cádiz, UCA, 1992.

21 Lazo, Alfonso: Retrato de fascismo rural en Sevilla. Sevilla, Universidad de Sevilla, 1998; Parejo, José Antonio: La Falange en la Sierra Norte de Sevilla (1934-1956). USE, 2004 y Señoritos, Jornaleros y falangistas. Sevilla, Bosque de Palabras, 2008; García, José Ma $\mathrm{M}^{\mathrm{a}}$, Las víctimas de la represión militar en la provincia de Sevilla (1936-1963). Sevilla, Aconcagua, 2012; Peral, Aurelio: La represión franquista durante la posguerra y la reconstrucción del movimiento obrero en Sevilla: 1940-1976 (Tesis, UNED, 2011); Ortiz, Juan: Del golpe militar a la Guerra Civil: Sevilla, 1936. Sevilla, R.D., 2006 y La Guerra Civil en Andalucía. Granada, Caja Granada, 2008; RÍO, Ángel del y Acosta, Gonzalo: El Canal de los Presos (1940-1962). Barcelona, Crítica, 2004 o "El Canal de los Presos: Memoria viva de los esclavos de Franco", en Lugares de la memoria: Golpe militar, represión y resistencia en Sevilla. Sevilla, Aconcagua, 2014, pp. 151-158 y Andaluces en los campos de Mauthausen. Sevilla, CENTRA, 2006 (y 2014).

22 Sánchez, Pura: Individuas de dudosa moral. La represión de las mujeres en Andalucía (1936-1958). Barcelona, Crítica, 2009; Sabuco, Assumpta: La isla del arroz amargo: andaluces y valencianos en las marismas del Guadalquivir. Sevilla, Fundación Blas Infante, 2004; Morales, Amalia: Género, mujeres, trabajo social y Sección Femenina. UGR, 2010; Sánchez, Francisco: Las Cátedras Ambulantes de la Sección Femenina de FET y de las Jons en Málaga (1955-1977). Tesis, Málaga, 1998; Pérez, Heliodoro: Una escuela viajera: La cátedra ambulante de la SF de Huelva (1956-1977). Huelva: Diputación Provincial, 2004. 
des del campo andaluz y algunos de sus moradores y protagonistas: desde los más mediáticos, como Ian Gibson y sus diversas biografías de García Lorca, Machado o Queipo de Llano, o el pionero impulsor de las fuentes orales Ronald Fraser, con sus dos obras dedicadas a Mijas y su alcalde-topo, hasta el madrileño Jorge Marco y su monografía sobre el maquis granadino y los Hermanos Quero, o Peter Anderson, que en 2006 leyó su tesis en University of London sobre la complicidad vecinal con la represión en el valle cordobés de Los Pedroches ${ }^{23}$.

Este breve estado de la cuestión sobre la guerra y el franquismo en Andalucía tiene que hacer una parada en el revulsivo que han supuesto para su conocimiento los proyectos auspiciados institucionalmente por la Ley de Memoria Histórica y canalizados a través de la Junta de Andalucía y sus ocho universidades. La financiación pública para abordar la elaboración del portal "Todos los Nombres" y el "Mapa de Fosas", así como la actuación de los Tribunales de Responsabilidades Políticas, la masonería, o el exilio, han contribuido a que hoy podamos afirmar que pocas regiones españolas cuentan con obras de síntesis como las que debemos a esta investigación sistemática y en equipo. Tanto Fernando Martínez, en Almería, como Diego Caro Cancela en Cádiz, Cristóbal García en Huelva, Manuel Morales y los ya citados Arcas Cubero y García Montoro, en Málaga, Salvador Cruz Artacho en Jaén, o Leandro Álvarez Rey en Sevilla, son algunos de los especialistas en Republicanismo y Restauración, que se han hecho responsables de dichos proyectos ${ }^{24}$.

Por último, debemos citar a tantos profesores de Educación Secundaria que realizan una gran labor fuera de las universidades, con la cobertura o no de instituciones como el Centro de Estudios Andaluces, en Dos Hermanas, o el Patronato Niceto Alcalá Zamora, en Priego de Córdoba; la Fundación Blas Infante y el Ateneo de Sevilla; el Instituto de Estudios Almerienses o Giennenses, y los diversos grupos que sostienen el Plan Andaluz de Investigación. Es el caso de Maribel Ruiz, José Luis Casas y Francisco Durán, u otros muchos adscritos a asociaciones de memoria como Andrés Fernández y Maribel Brenes, o Juan Hidalgo, cuya tesis analiza la represión militar de Granada. Merece destacarse también la Fundación de Estudios Sindicales de CC.OO, donde Eloísa Baena, Alfonso Martínez Foronda, Manuel Bueno y otros más vienen realizando una labor encomiable en su estudio del sindicalismo, el movimiento obrero y estudiantil en Andalucía a partir de las huelgas de 1962; las deportaciones y torturas del estado de excepción de 1969, o la resistencia ante el TOP hasta $1976^{25}$.

23 Citaremos sólo la última obra de Antonio Cazorla, Miedo y progreso: Los españoles de a pie bajo el franquismo, 1939-1975. Madrid, Alianza, 2016 y la primera de Ian Gibson, La muerte de Federico García Lorca. La represión nacionalista de Granada en 1936. Barcelona, Ibérica, 1978; Fraser, Ronald: Mijas: República, guerra, franquismo en un pueblo andaluz. Barcelona, Antoni Bosch, 1985 y Escondido: el calvario de Manuel Cortés. Barcleona, Crítica, 2006; Marco, Jorge: Hijos de una guerra. Los hermanos Quero y la resistencia antifranquista. Granada, Comares, 2010; Anderson, Peter: The Francoist Military Trials. Terror and Complicity, 1939-1945. New York, Routledge, 2010.

24 Martínez, Fernando (coord.): Los andaluces en el exilio del 39. Sevilla, CENTRA, 2015; Gómez, Miguel, Martínez, Fernando, Barragán, Antonio (coords.): El "botín de guerra" en Andalucía. Cultura represiva y víctimas de la Ley de Responsabilidades Politicas, 1936-1945. Madrid, Biblioteca Nueva, 2015; Álvarez, Leandro y Martínez, Fernando (coords.): Los masones andaluces de la República, la guerra y el exilio: Diccionario biográfico. Sevilla, USE, 2014; Gómez, Miguel y Martínez, Fernando (coord.): La Memoria de todos: las heridas del pasado se curan con más verdad. Sevilla, Fundación Alfonso Perales, 2014.

25 Ruiz, Maribel: Historia del movimiento obrero y las movilizaciones sociales en Almería. Almería, UAL, 2013; Casas, José Luis y Durán, Francisco (coords): El republicanismo en la historia de Andalucía. Córdoba, Patronato Niceto Alcalá-Zamora, 2001; Brenes, Maribel y Fernández, Andrés: 1937. Éxodo Málaga Almería. Nuevas 


\section{Los temas de interés}

Además de las materias apuntadas con anterioridad, existen hitos de nuestro tiempo presente que no siempre han despertado el interés de los historiadores o han alcanzado un adecuado tratamiento. Entre ellos se encontraría el estudio de la Edad de Plata y las campañas educativas contra el analfabetismo, el regionalismo, o la anhelada reforma agraria contra la oligarquía caciquil, durante la II República. Por otra parte, sobresalen los movimientos insurreccionales que tuvieron repercusión en todo el país, desde la Sanjurjada de agosto de 1932, en Sevilla, hasta los sucesos de Casas Viejas en 1933, que costaron el Gobierno a Azaña, o los ecos de la revolución de octubre de 1934 en Málaga, Jaén o Cádiz. Javier Tusell, Pilar Ballarín o Paco Cobo, entre otros, han sido algunos de los autores que definieron estos intereses, con mayor o menor predicamento, desde los ochenta ${ }^{26}$.

Los tres años de conflicto armado han mostrado también peculiaridades regionales, como el análisis de la guerra psicológica de Queipo de Llano, en el contexto de la resistencia sevillana; el avance de la "Columna de la Muerte" desde Riotinto hasta Badajoz, o la toma de Málaga "la roja" por el XIII Corpo Voluntarie de Mussolini, con la simultánea huida a pie de su población, recogida en artículos, monografías y varios documentales que sí que cuentan con abundantes fuentes orales. Tras la caída, el 7 de febrero de 1937, los refugiados de "la desbandá" en Almería sufrirían también el bombardeo nazi de la ciudad, provocado tras el incidente del Deutschland en la rada de Ibiza, un suceso de repercusión internacional narrado por algunos supervivientes en Bombas y Olvidos. Un mes más tarde, en mayo de 1937 y en el contexto de guerra intestina en el Frente Popular, surgió el Caso Maroto, al que Miquel Amorós apodó "el Durruti del sur" y el "héroe del anarquismo andaluz", como líder de una columna escindida del XXIII Cuerpo del Ejército Republicano, con sede en Guadix y Baza ${ }^{27}$.

fuentes de investigación. Aristipi, 2016; Hidalgo, Juan: Represión y muerte en la provincia de Granada: 19361950. 2 Vols. Almería, Arráez, 2014; Martínez, Alfonso: La conquista de la libertad: historia de las Comisiones Obreras de Andalucía. Sevilla, Fundación Estudios Sindicales CC.OO. 2003; El sindicalismo en Andalucia: el franquismo y la transición democrática. Jaén, UJA, 2009; VV.AA: La cara al viento: Estudiantes por las libertades democráticas en la Universidad de Granada (1965-1981). Sevilla, Fundación CC.OO, 2012 y La dictadura en la dictadura: detenidos, deportados y torturados en Andalucía durante el Estado de Excepción de 1969. Córdoba, El Páramo, 2011 o Martínez, Alfonso, Sánchez, Pedro, Baena, Eloísa: La resistencia andaluza ante el Tribunal de Orden Público en Andalucía: 1963-1976. Sevilla, Fundación CC.OO, 2014.

26 Tusell, Javier: Oligarquía y caciquismo en Andalucia (1890-1923). Barcelona, Planeta, 1976; Ballarín, Pilar: "El proceso de escolarización en la provincia de Almería (1850-1900)", Historia de la Educación, 5, 1986, pp. 215-234 y Rodríguez, Óscar: Pupitres vacíos. La escuela rural de post-guerra. Almería, 1939-1953. Almería, IEA, 2015; Cobo, Francisco: Revolución campesina y contrarrevolución franquista en Andalucía. Granada, UGR, 2004; Márquez, Francisco: Las sublevaciones contra la Segunda República. La Sanjurjada, octubre de 1934, Julio de 1936 y el Golpe de Casado. Madrid, Síntesis, 2010; Gutiérrez, José Luis: “Andalucía y el anarquismo (1868-1936)'”, Ayer, 45, 2002, pp. 171-196 y, sobre Casas Viejas, Cuadernos para el diálogo, 22, 2007, pp. 28-35.

27 Gutiérrez, José Luis et alii: La resistencia en Sevilla: Un intento de derrocar a Queipo. Sevilla, Aconcagua, 2012; Espinosa, Francisco: La columna de la muerte: el avance del ejército franquista de Sevilla a Badajoz. Barcelona, Crítica, 2003; Barranquero, Encarnación y Prieto, Lucía: Población y Guerra Civil en Málaga: Caída, éxodo y refugio. Málaga, CEDMA, 2007 o Majada, Jesús y Bueno, Fernando: Carretera Málaga-Almería (Febrero de 1937). Málaga, Calagrama, 2006; Quirosa, Rafael: "El bombardeo de Almería por la escuadra alemana", Boletín IEA, 5, 1985, pp. 189-206 o Rodríguez, Eusebio: Los refugios de Almería. La arquitectura del miedo. Almería, Guante Blanco, 2016; Amorós, Miquel: Maroto, el héroe. Una biografía del anarquismo andaluz. Barcelona, Virus, 2011. 
Finalmente, otro hito novedoso en la historiografía andaluza de la guerra civil, es el estudio de la quinta columna y el boicot al Gobierno Negrín, desde Lanjarón hasta Elche y las tres capitales del Estado: Valencia, Barcelona y el Madrid del "¡No pasarán!" 28 .

Tras la proclamación de la Victoria el 1 de abril de 1939, los trabajos dedicados a la implantación del Nuevo Estado y los juicios sumarísimos de primera hora, se han multiplicado paralelamente a la apertura de los archivos militares. Junto a las crónicas provinciales ya citadas, merece destacarse el reciente estado de la cuestión sobre la represión en Andalucía, publicado en la colección homónima de "Cuadernos de Historia Contemporánea" del CENTRA, o los compendios reseñados sobre el Botín de guerra o El exilio andaluz de 1939. Obras de síntesis complementadas por otras sobre el exilio literario, un trabajo coordinado desde Córdoba por María José Porro y Blas Sánchez, o las andaluzas que llegaron a México entre 1939 y 1948 . Hace poco se ha leído también en Almería la última tesis sobre el estado sanitario de los campos de concentración en Francia, a cargo de Rubén Mirón, y se están llevando a cabo otras sobre el desembarco en los del norte de África. Y en el ámbito de las depuraciones profesionales, merecen destacarse investigaciones como las de María del Campo Pozo sobre el magisterio en Málaga, o Antonio Sánchez Cañadas en Almería ${ }^{29}$.

Sobre el maquis y la oposición política de toda la región trata el Ejército Guerrillero de Andalucía, entre 1945 y 1952, firmada por Eusebio Rodríguez Padilla, mientras que de esa "resistencia silenciosa" menos vistosa y conocida, contamos dos casos apasionantes sin monografía: el del "Parte Inglés" en Almería y el de "Las Centenas" en Sevilla, dos símbolos coetáneos de la persecución de las redes de solidaridad antifascista y socorro rojo en $1941^{30}$.

En cuanto a las estrategias de supervivencia de la posguerra, hay un tema estrella compartido por las Universidades de Granada y Almería, como es el auge del mercado negro en el medio rural hasta el 15 de junio de 1952, fecha en que el gobierno de Franco anuncia la salida de la autarquía y el fin de las cartillas de racionamiento. El análisis del estraperlo de subsistencia frente a los auténticos beneficiarios del contrabando por canales oficiales, como la Fiscalía de Tasas y la Comisaría de Abastecimientos y Transportes, es así una de las grandes contribuciones andaluzas a esa historia socioeconómica de la dictadura emprendida por Carlos Barciela. Migas con miedo de Óscar Rodríguez y Hambre de siglos de Miguel Ángel del Arco, son los mejores exponentes de esa línea de trabajo, continuada por Gloria Román en Delinquir o Morir. En sintonía con el Grupo Histagra de la Universidad de Santiago,

28 Rodríguez, Sofía: Quintacolumnistas. Las mujeres del 36 en la clandestinidad almeriense. IEA, 2008 y (con Rodríguez, Óscar), "La Quinta Columna durante la Guerra Civil en Andalucía”, Andalucía en la Historia, 46, 2014, pp. 72-77.

29 Cobo, Francisco (coord.): La represión franquista en Andalucia: balance historiográfico, perspectivas teóricas y análisis de resultados. Sevilla, CENTRA, 2012; Porro, María José y Sánchez, Blas (coords.): El exilio literario andaluz de 1939. Córdoba, Diputación Provincial, 2011; Martínez, Alba: Andaluzas exiliadas en México tras la guerra civil (1939-1948). Almería, UAL, 2015; Pozo, Mª Campo: La depuración del magisterio nacional en la ciudad de Málaga. Diputación Provincial de Málaga, 2001; Sánchez, Antonio: Memoria y dignidad: depuración y represión del magisterio almeriense durante la dictadura del general Franco. Sevilla, Corduba, 2007.

30 Rocamar-29 Letras, El parte Inglés. La represión franquista en Almería, 1942 (Documental, 2010) y Rodríguez, Óscar: Migas, con miedo..., op. cit., pp. 109-117; Peral, Aurelio: "La represión política en Sevilla durante el franquismo", Espacio, Tiempo y Forma, 27, 2005, pp. 227-263. 
ellos han hecho de las "armas de los débiles" en el medio rural el leit motiv de su investigación, siguiendo los estudios sociales, subalternos y poscoloniales de James Scott o Ranahit Guha. El furtivismo de los Rebeldes Primitivos de Hobsbawm, o el "ecologismo de los pobres", cultivado por ambientalistas como Manuel González de Molina, vuelven así a primer plano de la actualidad, cobrando una nueva dimensión política al trabajar el franquismo, porque como indica Pura Sánchez, cuando la dictadura te invitaba a morir de asco, de hambre y de miedo, vivir se convirtió en un acto de resistencia ${ }^{31}$.

Si estos grandes hitos marcan la investigación de los años 40 en Andalucía, la liberalización y posterior Plan de Estabilización de 1959 pondrían las bases de su actual estructura productiva. Nos referimos, por una parte, a las inversiones estatales del Instituto Nacional de Colonización, de Industria y del Ministerio de Información y Turismo, para implantar sus grandes proyectos en el campo, la ciudad y el litoral. Lo que se tradujo en los planes de regadío desde la Barca de La Florida en Cádiz, hasta San Isidro en Almería; junto a los polos de desarrollo que dieron lugar al despegue de la empresa aeronáutica CASA, el frustrado Plan Jaén o los conflictos de Intelhorce en Málaga, y la salvaje especulación urbanística de la Costa del Sol. Por otra parte, encontraríamos la gran válvula de escape para quienes no obtuvieron parcelas como colonos, ni se vieron beneficiados en forma alguna por esa inversión: esos miles de emigrantes andaluces que protagonizaron tanto el éxodo rural hacia las grandes capitales, a partir de los años cincuenta, como los desplazamientos continentales hasta Francia, Suiza o Alemania, en fechas próximas a la muerte de Franco. Aspectos, en definitiva, de una importancia capital para la región y que han sido abordados tanto por estudios provinciales tempranos, como el de Romero y Zoido de 1977, sobre la colonización de Cádiz y Córdoba, a la tesis de Antonio Cazorla, Desarrollo sin Reformistas, publicada en 1999 en Almería, o el más reciente de Jiménez Díaz sobre la memoria de la Costa Tropical; hasta los de Teresa Ortega para Granada, Carmen Rosa García en Málaga, David Martínez para Jaén o Antonio Herrera en Sevilla. Asimismo, entre 2009 y 2012 han aparecido síntesis sobre la economía regional, por Antonio Parejo, las Transformaciones culturales de la sociedad rural andaluza, de Rodríguez Becerra y Macías, o sobre la emigración a cargo de Enriqueta Cózar Valero ${ }^{32}$.

Hasta aquí el repaso por los temas mejor conocidos de la guerra civil y la dictadura, así como de los autores o escuelas encargadas de su investigación y rescate del

31 Rodríguez, Óscar: Migas con miedo. Prácticas de resistencia al primer franquismo. Almería, 1939-1953. UAL, 2008; Del Arco, Miguel Ángel: 'Hambre de siglos'. Mundo rural y apoyos sociales del franquismo en Andalucía Oriental (1936-1951). Granada, Comares, 2007; Román, Gloria: Delinquir o morir. El pequeño estraperlo en la Granada de posguerra. Granada, Comares, 2015; González de Molina, Manuel (ed.): La historia de Andalucía a debate. Vol. I. Campesinos y jornaleros. Barcelona, Anthropos, 2000.

32 Romero, J.J. y Zoido, F.: Colonización agraria en Andalucia. (Estudios sobre las actuaciones para la transformación del espacio rural en las provincias de Cádiz y Córdoba). Sevilla, USE, 1977; Jiménez, José F.: Relatos biográficos de agricultores: memoria de la revolución agrícola en la costa de Almería y Granada. Comares, 2010; Ortega, Teresa: Trabajadores y jornaleros contra patronos y verticalistas: conflictividad laboral y reivindicación democrática en una provincia periférica y escasamente desarrollada: Granada, 19361982. UGR, 2001; García, Carmen Rosa: Franquismo y Transición en Málaga ...op. cit; Martínez, David y Cruz, Salvador: Protesta obrera y sindicalismo en una región “idilica”... op. cit., Herrera, Antonio: La construcción de la democracia en el campo. UJA, 2007; Parejo, Antonio: Historia económica de Andalucía contemporánea. De finales del siglo XVIII a comienzos del XXI. Madrid, Síntesis, 2009; Cózar, Enriqueta: La emigración exterior de Almería. Granada, UGR, 1984 o Inmigrantes andaluces en Argentina durante la Guerra Civil y la posguerra (1936-1960). Sevilla, CENTRA, 2012. 
olvido. Con honrosas excepciones, puede decirse que si la generación española de posguerra fue sepultada por esa "cultura del silencio" impuesta por el franquismo, la historiografía andaluza -tan pródiga en bibliografía- ha dado la espalda durante años a sus supervivientes, en lugar de escucharles. Como traté de argumentar al principio, más allá de la mera contribución de detalles episódicos y narrados en primera persona, las fuentes orales nos brindan un cambio de lentes para atender a aspectos que habían pasado desapercibidos al olvidar a los sujetos históricos, el imaginario y las construcciones culturales que había tras ellos. Un interés que en cambio surge, precisamente, cuando se rompe con el nihilismo de ese "tiempo de silencio". 